\title{
Molecular Evidence-Based Use of Bone Resorption-Targeted Therapy in Prostate Cancer Patients at High Risk for Bone Involvement
}

\author{
Dimitrios Karamanolakis, ${ }^{1,2}$ John Bogdanos, ${ }^{1,2}$ Antigone Sourla, ${ }^{3}$ Constantine Milathianakis, ${ }^{1,2}$ \\ Athanassios Tsintavis, ${ }^{2}$ Peter Lembessis, ${ }^{1,3}$ Roxane Tenta, $^{1}{ }^{\text {Despina Tiblalexi, }}{ }^{1}$ and Michael Koutsilieris ${ }^{1}$ \\ ${ }^{1}$ Department of Experimental Physiology, Medical School, University of Athens, Goudi-Athens, Greece \\ ${ }^{2}$ Urology Clinic, "METAXA" Anticancer Hospital, Piraeus, Greece \\ ${ }^{3}$ Endo/OncoResearch Diagnostic \& Therapeutic Medical Center, Platia Mavilis, Athens, Greece
}

Accepted September 23, 2002

\begin{abstract}
Background: To improve median survival of patients with prostate cancer that has metastasized to bone, we need to better understand the early events of the metastatic process in skeleton and develop molecular tools capable of detecting the early tumor cell dissemination into bones (micrometastasis stage). However, the initial phase of tumor cell dissemination into the bone marrow is promptly followed by the migration of tumor cells into bone matrix, which is a crucial step that signals the transformation of micrometastasis to macrometastasis stage and clinically evident metastasis. The migration of cancer cells into bone matrix requires the activation of local bone resorption. Such an event contributes to tumor cell hiding/ escaping from high immunologic surveillance of bone marrow cells. Within bone matrix, tumor cells are establishing plethoric cell-cell interactions with bone marrow-residing
\end{abstract}

\section{Introduction}

The most important clinical manifestation of cancer, which defines treatment strategy, disease prognosis and overall survival, is tumor cell dissemination (metastasis) into organs distant from the primary tumor (1). The process of metastasis implicates a cascade of events, involving angiogenesis, detachment from the primary tumor (cell mobility), migration into the adjacent tissue (invasion), adhesion onto the wall and entry into the local vessels, dissemination through the systemic circulation, survival in peripheral blood, extravasations, attachment onto specific organs (seed and soil theory), and local ectopic/metastatic growth in host tissue (1-3).

Correspondence and reprint requests should be addressed to: Michael Koutsilieris, MD, PhD, Department of Experimental Physiology, Medical School, University of Athens, GoudiAthens 115 27, Greece. Phone: 3010-7462597; fax: 30107775295; e-mail: mkouts@medscape.com. cells, ensuring their survival and growth. Recently, RTPCR detections of tumor marker transcripts, such as PSA and PSMA mRNA performed in RNA extracts of peripheral blood nucleated cells and bone marrow biopsy, have enabled the stratification of patients with clinically localized prostate cancer being of high risk for extraprostatic disease and bone involvement. Therefore, it is conceivable that bisphosphonate blockade of bone resorption can inhibit the migration of tumor cells into bone matrix during the early phase of disease dissemination into bone marrow (micrometastasis stage). Consequently, assessment of the efficacy and efficiency of bisphosphonates to arrest the evolution of bone lesions in this particular clinical setting of patients with clinically localized prostate cancer and positive molecular staging status (high risk for bone involvement) is warranted.

There are serious concerns stemming from the fact that bones correspond to the most prevalent site of prostate cancer metastases, producing mainly, but not exclusively, the osteoblastic reaction of skeletal tissue (3-7). That is because the actual number of the metastatic foci into bone is the single and the most powerful adverse prognostic factor that predetermines, sooner or later, lethal outcome $(8-10)$. In addition, the extension of skeletal lesions ( $>6$ foci) correlates strongly with limited response to androgen ablation therapy; bony lesions are, almost always, the exclusive sites of disease progression to hormone refractory stage $(11,12)$. Notably, disease progression to hormone refractory stage in bones develops while androgen ablation therapy provides still complete control of disease at the primary site $(9,10,13,14)$. Apparently, bone constitutes a favorable microenvironment of extreme biologic importance facilitating the development of hormone- and chemotherapy-refractory tumor biology $(5-7,9,10)$. 
The altered tumor cell biology in bone metastasis is secondary to interactions of prostate cancer cells with bone cells, which can promote both the growth and survival of metastatic cancer cells locally $(2,7,9-11)$. Among bone-derived growth factors abundantly produced by the microenvironment of skeletal metastasis, the members of the transforming growth factor beta family (TGF- $\beta$ s) are known to favor the metastatic process (5-7). The TGF- $\beta$ s can amplify prostate cancer cell invasion capabilities in vivo and in vitro, stimulating tumor cell production of known biochemical modulators of tumor biology, such as parathyroid hormone-related peptide (PTHrP), a known survival factor for tumor cells and mediator of bone resorption, locally $(3,5,7,10)$. Recently, the osteoclasts differentiation factor (RANK-ligand), a member of the tumor necrosis factor family (TNF family), documented to mediate the effects of PTHrP on osteoclast-mediated bone resorption stimulated by both breast and prostate cancer cells in experimental animals (15). Furthermore, other local bioregulators such as insulin-like growth factors (IGFs), basic fibroblast growth factors (bFGF), urokinase-type plasminogen activator (UPA)/uPA receptor bioregulation system, interleukins (ILs), endothelin-1, and bone morphogenetic proteins (BMP, particularly BMP-6) have shown to play a pivotal role in the osteoblastic metastasis from prostate cancer (3-11,16-20) (Fig. 1).

Recently, biochemical markers of bone resorption were increased both in the serum and urine of patients with advanced stage prostate cancer, suggesting that prominent bone formation in bone metastasis is actively coupled to an osteoclast-mediated bone resorption (3-6). Therefore, it appears that pharmacologic targeting of bone resorption can become an

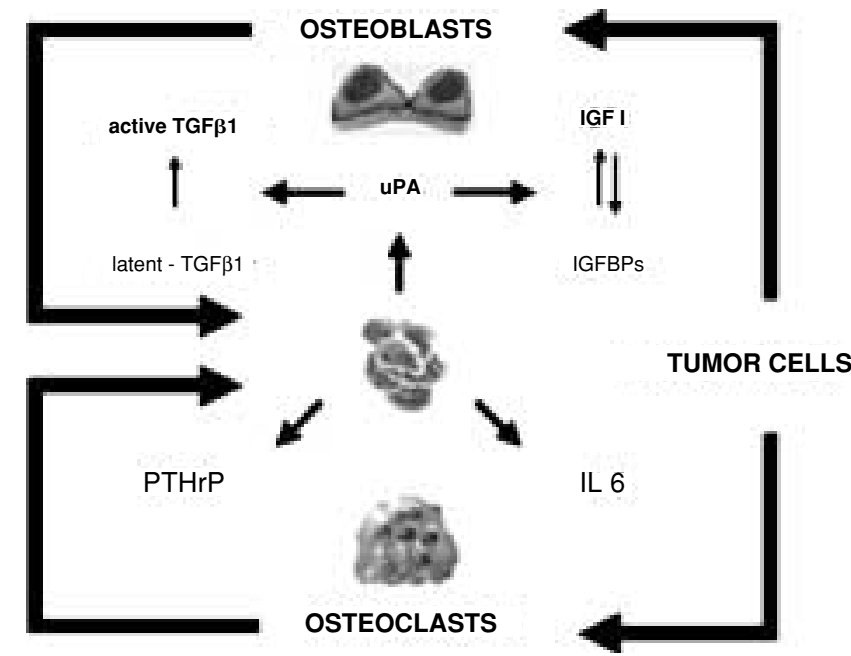

Fig. 1. Local mediators of tumor cell survival and tumor cell-induced osteoblastic reaction at the sites of skeletal metastasis in prostate cancer. Note the pivotal role of IL-6, PTHrP, and uPA/IGFBPs/IGFs/TGF- $\beta 1$ bioregulation system into these processes.

effective approach for a sizable number of patients with advanced prostate cancer (21). Furthermore, bone-derived growth factors, such as IGF-I, PTHrP, IL-6, bFGF, and TGF- $\beta 1$ documented to exert survival factor activity on tumor cells, protecting prostate cancer cells from chemotherapy-induced apoptosis $(9,10,22)$. These data generated the concept of anti-survival factor therapy (ASF therapy) in hormone refractory prostate cancer, which was designed to target the most important survival factor of bones, namely IGF-I (Fig. 2). This novel manipulation, a

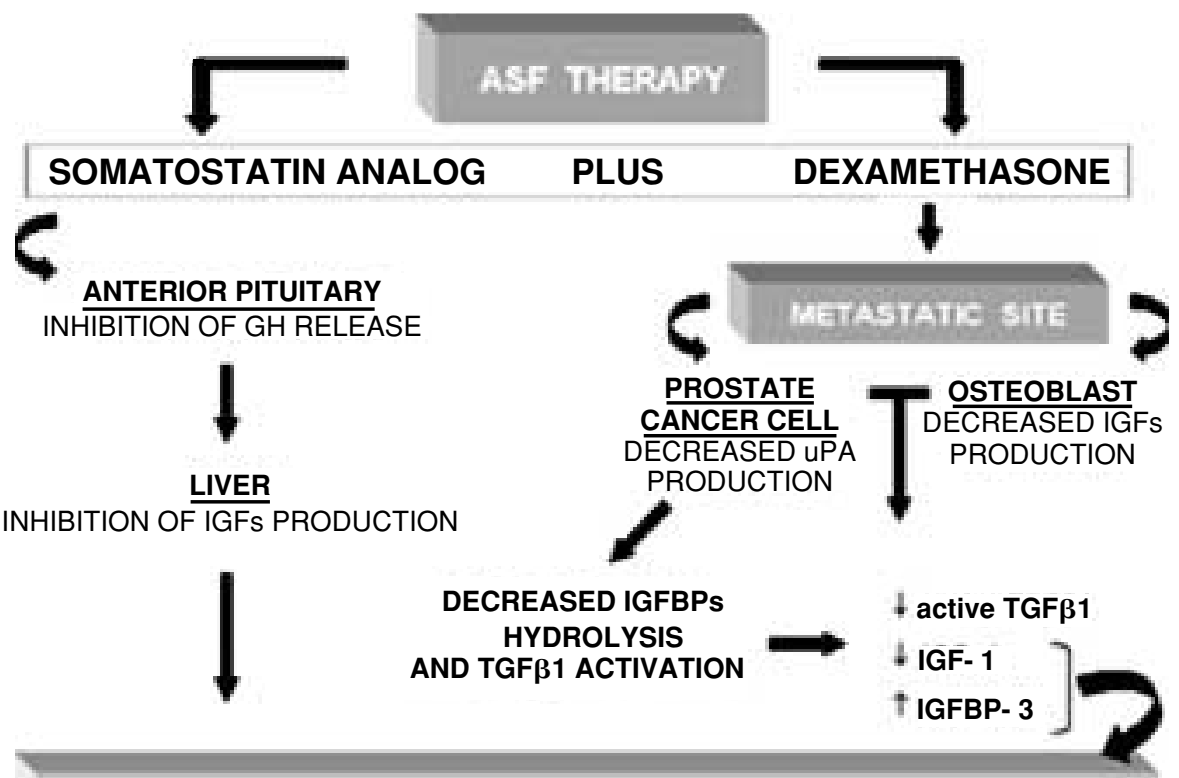

DECREASED SYSTEMIC AND LOCAL IGF-I BIOAVAILABILTY
Fig. 2. Schematic representation of the main pharmacologic cell targets and pathophysiologic mechanisms targeted by ASF therapy (practically an anti-IGF-I bioavailability therapy) using the combination of somatostatin analog and dexamethasone in the clinical setting of hormone refractory prostate cancer. 
paradigm of bone microenvironment-targeted therapy, produced objective and sustained clinical responses in androgen ablation of refractory prostate cancer $(23,24)$. However, it is fair to conclude that today's available anticancer therapies cannot improve the median survival of metastatic prostate cancer patients. Consequently, efforts should focus on understanding the early events of the metastatic process in skeleton and developing molecular methods for detecting early tumor cell dissemination into peripheral blood and bone marrow (micrometastasis stage) (25-27).

\section{The Use of Bisphosphonates in Prostate Cancer With Far Advanced Metastatic Disease in Bones}

Bisphosphonates are potent inhibitors of osteoclastmediated bone resorption, an action based predominantly on their ability to block the function of osteoclasts. Consequently, their use has been established in the management of medical disorders associated with an increased bone resorption, such as Paget's disease, multiple myeloma, osteolytic skeletal metastases in breast carcinoma, and the treatment of hypercalcemia associated with malignancy (21). Over the last decade they have been widely used in the management of osteoporosis, although at much lower dose regimens than those required in patients with overtly increased bone resorption. The exact mechanism by which bisphosphonates inhibit osteoclast activity has been recently clarified. Two major mechanisms have been described, depending on their chemical structure. Non-nitrogen-containing bisphosphonates, such as etidronate, clodronate, and tiludronate are intracellularly metabolized to substances toxic to the osteoclasts $(28,29)$. Nitrogen-containing bisphosphonates, such as alendronate, ibandronate, olpadronate, pamidronate, and residronate, interfere with specific enzymes of the mevalonate pathway, eventually leading to a disruption of the cytoskeletal integrity and intracellular signaling of osteoclasts, resulting in their early apoptosis $(30,31)$.

The rationale for the use of bisphosphonates in the management of metastatic prostate adenocarcinoma is not immediately obvious, given the predominant osteoblastic nature of these metastatic processes. The clinical use of the above agents in prostate cancer rests on a number of basic and clinical observations (32). There is ample evidence that prostate cancer metastases are also associated with increased bone resorption as determined by bone histomorphometry and biochemical markers of bone resorption (21,33-39). Notably in patients with metastatic prostate cancer, there is a progressive increase of urinary deoxypyridinoline excretion, which is associated with the increasing extent of bone metastases as evaluated by bone scan. In addition, there is a significant correlation between bone formation and bone resorption biochemical markers, suggesting the coupling between these two processes, although there is an apparent shift of the slope in favor of bone formation $(35,36,40)$. Furthermore, the unusual presentation of hypercalcemia and its favorable response to bisphosphonate therapy also suggest, under certain circumstances, that the resorptive component of the skeletal disease may become predominant even in prostate cancer with osteoblastic metastasis. The latter can be either radiologically detected and/or histologically proven by the presence of an increased number of osteoclasts in metastatic sites (35-37).

Prostate cancer cells express bone-resorbing factors, such as macrophage colony-stimulating factor (MCSF), PTHrP, IL-1, and IL-6. These bone-resorbing factors may in turn be responsible for inducing the expression of RANK-ligand, and thereby inducing osteoclastogenesis (41-43). In this context, bisphosphonates can decrease the skeletal morbidity associated with bone metastases in breast carcinoma and multiple myeloma by reducing the incidence of pathologic fractures and episodes of hypercalcemia $(44,45)$. In addition, there is in vitro evidence that bisphosphonates may inhibit the adhesion of prostate carcinoma cells to bone matrices or bone slices $(46,47)$. Another possible mechanism of action of bisphosphonates in prostate cancer is their potential ability to inhibit matrix metalloproteinases enzymatic activity (48). Furthermore, both in vitro and in vivo data indicate that zoledronic acid, a third-generation bisphosphonate, has shown to exert, apart from its anti-osteoclastic and antitumor activities, anti-angiogenic effects, inhibiting the proliferation of human endothelial cells in vitro and angiogenesis induced by bFGF in tissue chamber implants in mice (49).

However, establishing an effect of bisphosphonates on growth and development of bone metastases is no simple task. As a part of a large phase III protocol, including more than 3000 patients with solid tumors and well-documented bony metastases, zoledronic acid (4 mg) was compared with placebo in 422 patients with hormone-refractory prostate cancer and bone metastases $(50,51)$. Bone marker data from these trials confirmed that markers of bone resorption (N-telopeptide) as well as markers of bone formation (bone alkaline phosphatase) significantly reduced from baseline levels. More importantly, treatment with zoledronic acid resulted in a significant $(25 \%)$ reduction in the proportion of patients with a skeletal-related event (SRE) and significantly reduced the skeletal morbidity rate (SMR) for all SREs compared with placebo. Furthermore, zoledronic acid significantly delayed the time to first SRE compared with placebo and had an impressive effect on bone pain in this trial $(50,51)$.

Herein it is fair to outline that in past years several problems have marked the evaluation of bisphosphonates in metastatic prostate cancer because pain, the main complication of the bony metastases, is difficult to evaluate. Furthermore, most 
studies with prostate cancer patients have generally included a small number of patients with far advanced disease, and the absorption of bisphosphonates has been difficult to establish, particularly with the use of oral preparations. A recent evidenced-based review of available studies on the potential use of bisphosphonates has understandably called for further investigations to establish the role of these agents in the palliative management of patients with metastatic prostate cancer (52). Apparently, the early promise of the first-generation bisphosphonate etidronate (53) has not been proven in a double-blind, placebo-controlled design (54). Recently, open-ended studies suggested that clodronate intravenously used and in adequate doses provided significant pain relief in patients with bony metastases (55-58). However, the only placebo-controlled study of this bisphosphonate published is surprisingly confounded by concomitant use of anticancer treatment (estramustine phosphate), so that the disease response and outcome is hard to interpret solely as bisphosphonate's efficiency and efficacy (59). The use of pamidronate, a nitrogen-containing bisphosphonate, was reported that is producing a significant but generally short-lived response, requiring intravenous administration at frequent intervals (60-66). Similarly, olpadronate was effective in the palliation of bone pain in $70 \%$ of patients with metastatic prostate cancer when it is given intravenously and followed by oral maintenance therapy; its clinical responses parallel biochemical changes in bone resorption (65).

In conclusion, bisphosphonate's efficiency is currently under investigation, however, deemed to be of limited clinical use in far advanced prostate cancer. Moreover, any conclusion regarding the ability of bisphosphonates to slow or prevent the metastatic process in prostate carcinoma must await results of large, controlled studies in which the agents are administered early in the course of the natural history of this malignancy. Apparently, effectiveness of bisphosphonates in preventing the evolution of bone metastasis can be made only in the clinical setting of localized prostate cancer patients at high risk for extraprostatic disease-bone involvement detected by molecular staging.

\section{Understanding the Role of Bone Resorption at the Early Phase of Formation of Skeletal Lesions}

The local mechanisms of initiating the establishment of metastasis in bones includes recognition and attachment of tumor cells onto bone marrow, invasion of bone matrix, and development of cell-cell interactions with bone cells, leading to blastic, lytic, or mixed-type lesions (2-7). This local process is initiated by the arrival of tumor cells, via peripheral blood, into the metabolically active ("red") bone marrow. Theoretically, at initial arrival in bone marrow tumor cells should be more or less equally distributed into the red bone marrow-containing bones (2-4). Obviously, a threshold number of circulating-invading tumor cells per milliliter of bone marrow is necessary for the establishment of clinically evident bony metastases (2). Based on extensive animal model data, a single prostate cancer metastatic foci would require more than $10,000 \mathrm{tu}-$ mor cells circulating in the bloodstream $(5,17)$. Consequently, bones of higher red bone marrow content are expected to be more frequently and more intensively invaded by tumor cells $(4-7,67)$. Indeed, the predicted importance of red bone marrow content in the establishment of bony lesions is clinically confirmed by the frequency analysis of metastatic foci observed in bones rich versus bones poor in metabolically active bone marrow content $(68,69)$.

At the stage of initial invasion of tumor cells into bone marrow (micrometastasis stage), tumor cells are recognized by bone marrow as foreign invaders and are forced to live in the hostile microenvironment of the immunologically hyperactive bone marrow cells. Consequently, tumor cell survival is directly linked to their ability to escape the intense immunologic surveillance of host tissue. This can be easily achieved by migration into bone matrix where bone matrix-residing cells (mainly osteocytes/ osteoblasts) can protect and stimulate tumor cell proliferation by their production of growth/survival factors, such as IGFs, TGF- $\beta$ s, BMPs, bFGF, and PTHrP (Fig. 1).

Indeed, the migration of tumor cells into bone matrix signals the transformation of micrometastasis stage, a diffuse dissemination of tumor cells into bone marrow to macrometastasis stage, which is mainly characterized by focal development of bony lesions $(2-6,68)$. This mechanism, which enables the migration of tumor cells into bone marrow, involves the activation of osteoclast-mediated bone resorption locally. That includes tumor cell-mediated local attraction-fusion of circulating pre-osteoclasts to form mature osteoclasts, thereby initiating bone resorption and/or passive migration of tumor cells into bone matrix, capitalizing over the phenomenon of periodically activated bone resorption, a natural phenomenon that occurs approximately every 3-6 months at the bone remodeling units of red marrow-containing bones. There are no strong data to support the direct tumor cell resorption of bones in the absence of osteoclasts (Fig. 3). Therefore, osteoclast-mediated bone resorption is a crucial step for the formation of bone macrometastasis (3-7). Thereafter, late events taking place between tumor cells, already located into bone matrix and bone matrix-residing cells (osteoblast-osteocytes) will favor either the predominance of bone formation or the bone destruction, thereby resulting in the final histologic type of bony lesions (blastic, lytic or mixed) (Fig. 4). 


\section{A. TUMOR CELL DISSEMINATION INTO PERIPHERAL BLOOD}

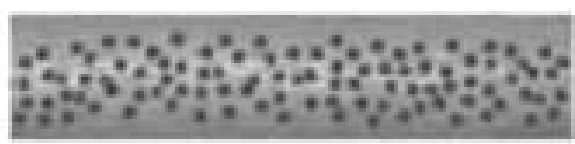

\section{B. TUMOR CELL INVASION INTO "RED” BONE MARROW}

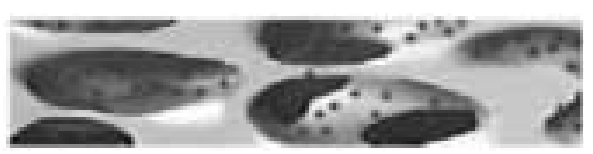

\section{TUMOR CELL INVASION INTO BONE MATRIX}

1. Naturally occuring activation of bone resorption (bone remodeling unit)

2. Tumor cell - mediated bone resorption (attraction-fusion of pre-osteoclasts to form osteoclasts)

3. Direct tumor cell-mediated bone resorption (absence of osteoclasts)

Fig. 3. Illustration of the initial steps implicated in the formation of bone metastasis. (A) Dissemination and survival of prostate cancer cells in the peripheral blood. (B) Dissemination of tumor cells into the metabolically active red bone marrow (micrometastasis stage). (C) Activation of bone resorption, which enables the migration of tumor cells into bone matrix and the establishment of macrometastasis in bones.

\section{Stratification of Risk for Bone Involvement in Patients With Clinically Localized Prostate Cancer}

Apparently, our inability to treat advanced prostate cancer is mainly caused by the limitations of our diagnostic tools to detect bony lesions at early phase of tumor cell dissemination into bone marrow, the socalled micrometastasis stage. It is conceivable that development of molecular tools enabling the detection of micrometastasis stage could provide the opportunity for an effective therapeutic intervention right before tumor cell migration into bone matrix (macrometastasis stage).

Indeed, the enhanced sensitivity nested RT-PCR detection of prostate-specific antigen (PSA) and/or prostate specific membrane antigen (PSMA) mRNA is capable of detecting the presence of 1 prostate cell in $10^{6}$ noncancer peripheral blood nucleated cells and bone marrow aspirates (70-75). Initially, this enhanced sensitivity RT-PCR assay was thought to be an excellent approach for evaluating clinical samples due to PSA and PSMA specificity to prostate cells. However, PSA mRNA expression was documented in non-prostate origin cell lines and enhanced sensitivity PCR assays revealed the presence of illegitimate PSMA transcripts in peripheral blood leukocytes and other non-prostate cancer cell lines $(76,77)$. Therefore, any further attempt to obtain enhanced analytical sensitivity PCR assays was bound to suffer a decrease in the assay's specificity, thereby compromising the clinical usefulness of molecular staging in patients with prostate cancer (75).

Recently, the clinical relevance of molecular staging was reassessed by modifying the definition of a positive and negative RT-PCR detection, using certain clinically established prerequisites (78-80). Based on these prerequisites, positive molecular staging status is awarded only to samples tested positive for both PSA and PSMA transcripts. Consequently, samples found, in a repetitive manner, to be of a differential RT-PCR status for tumor markers detection (PSA positive/PSMA negative or vice versa) were classified as negative and differential RT-PCR detection was attributed to illegitimate transcription $(78,79)$. In addition, the sensitivity of the RT-PCR assays was set at 3-5 LNCaP prostate cancer cells in $10^{6}$ peripheral blood nucleated cells for the screening of patients samples, which is considered to reflect tumor cell concentration, a more relevant criteria for the establishment of metastasis in animal models (78). These specificity/sensitivity

\section{bone resorption}

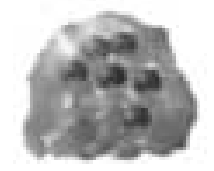

Osteolytic or mixed metastasis
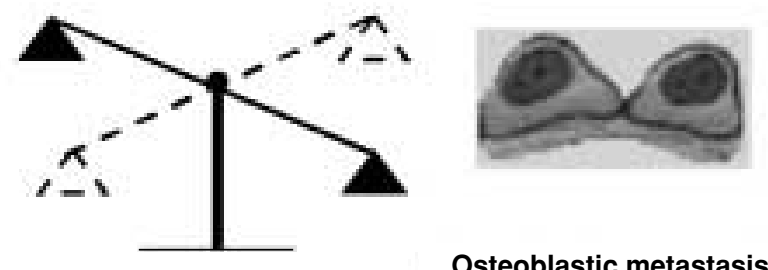

Osteoblastic metastasis
Fig. 4. Schematic illustration of the histologic types of bony lesions, a result of specific cell-cell interactions established at the sites of metastasis. Tumor cell interactions with osteoblasts and osteoclasts can be coupled in a manner that can favor either bone formation or bone resorption, resulting in the development of osteoblastic, osteolytic, and/or mixed histologic types of bony lesions. 
RT-PCR conditions were tested on total RNA extracts obtained from blood donor clinics (blood samples of young men and women) expected anyway to be negative for PSA and PSMA transcripts, RNA extracts of samples from patients with biopsy-proven benign prostatic hyperplasia, and RNA samples of patients with far advanced disease in bones $(78,79)$.

Indeed, data of such comprehensive molecular staging procedure performed in peripheral blood (PB) and bone marrow biopsy (BM) showed strong correlation of positive PSA and PSMA RT-PCR detections with (1) PSA levels $\geq 20 \mathrm{ng} / \mathrm{ml}$ at diagnosis, (2) Gleason's scores $\geq 7$ at diagnosis, and (3) time-tobiochemical failure shortly after radical prostatectomy in patients with clinically localized prostate cancer. Under these experimental conditions, molecular staging enabled the stratification of patients into groups with (1) low risk for bone involvement-negative analysis for both PSA and PSMA in PB and BM, (2) high risk for bone involvement-positive analysis for both PSA and PSMA in PB and BM, and (3) intermediate risk for extraprostatic involvement-positive analysis for both PSA and PSMA at PB but negative for both PSA and PSMA in BM $(74,75)$. We recently analyzed the results of molecular staging in 111 patients with

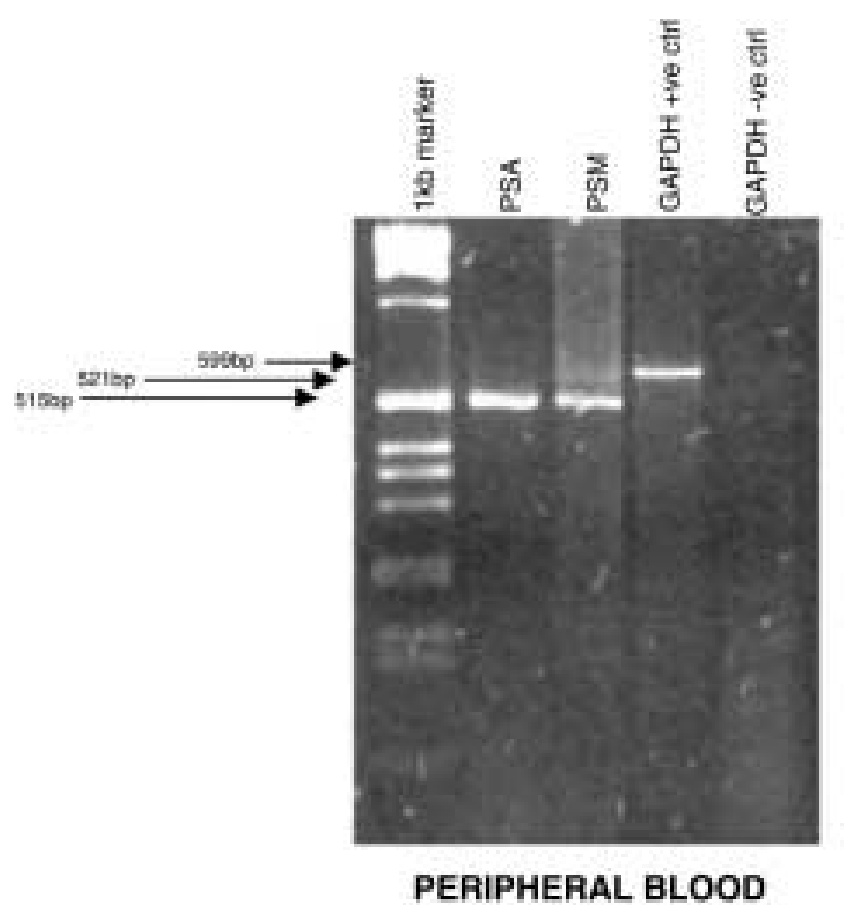

clinically localized prostate cancer (80). These data confirm the previously reported association of positive molecular staging with higher PSA and Gleason's score values at diagnosis as compared with those of negative molecular staging. Kaplan-Meier analysis and log-rank tests reveal that the median time-to-PSA failure (biochemical failure) was significantly different between groups with positive and negative molecular staging either in PB or BM. During the follow up, $20 \%$ of the patients with positive molecular staging have become positive for bony metastasis, as detected by bone scan and confirmed by computerized tomography (CT). These data suggest that positive molecular staging in $\mathrm{PB}$ and $\mathrm{BM}$ can define the patients of high risk for disease progression/extraprostatic growth (80).

Consequently, comprehensive molecular staging procedure is able to stratify patients with clinically localized disease into groups of high risk and low risk for extraprostatic disease and bone involvement (Fig. 5).

\section{Conclusion}

Because, osteoclast-mediated bone resorption has a permissive role for the establishment of bony

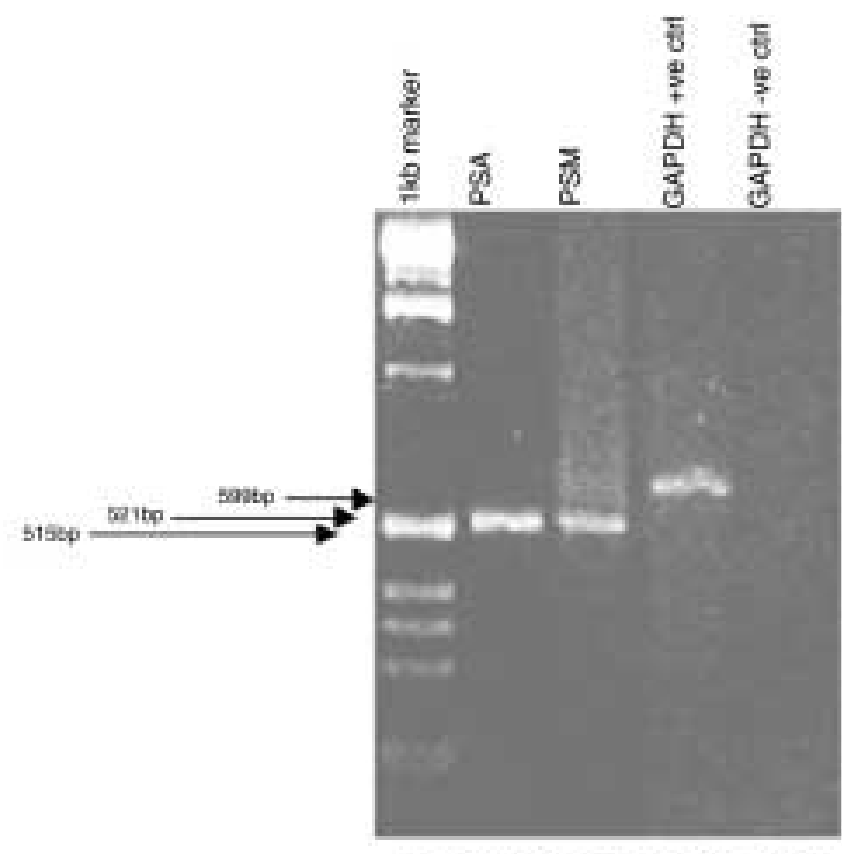

BONE MARROW BIOPSY

Fig. 5. An example of comprehensive molecular staging in a clinically localized prostate cancer patient using RT-PCR detection of PSA and PSMA transcripts in PB and BM as developed by the clinical prerequisites previously described (74,75). This example represents the case of patient with PSA $=5.6 \mathrm{ng} / \mathrm{ml}$; Gleason's score $=7(4+3)$ prostatic adenocarcinoma (transrectal ultrasound-guided biopsy); negative evaluation for metastasis as assessed by bone scan, metastatic survey (x-rays) and CT; who tested positive for both PSA and PSMA in PB and BM. He underwent immediate radical prostatectomy (RP) and experienced early

biochemical failure (PSA $=1.5 \mathrm{ng} / \mathrm{ml}$ ) 6 months after RP. Then he was prescribed local irradiation therapy plus temporary combined androgen blockade (CAB; for 3 months). Twelve months after irradiation therapy, PSA was $9.0 \mathrm{ng} / \mathrm{ml}$, and the bone scan revealed the presence of multiple sites of bone lesions throughout the spine and pelvis. The latter were confirmed by CT. Notably, RT-PCR-based indications for probable extraprostatic disease and bone involvement were given approximately 2 years before the final diagnosis of stage D2 disease. 
macrometastasis and comprehensive molecular staging can detect prostate cancer patients at high risk for bone involvement, it is reasonable to postulate that bisphosphonate-based blockade of osteoclastmediated bone resorption at this initial stage of the disease dissemination into red bone marrow can inhibit the formation of macrometastasis by inhibiting the migration of tumor cells into bone matrix $(79,80)$.

\section{Acknowledgments}

The authors are thankful for the support of the Research Account, University of Athens; General Secretariat of Research \& Technology, Ministry of Development; and Central Council for Health, Ministry of Health.

\section{References}

1. Stamey TA, McNeal JE. (1992) Adenocarcinoma of the prostate. In: Walsh PC, Retik AB, Stamey TA, et al. (eds). Campbells Urology, volume 1. Philadelphia: Saunders; pp. 1159-1221.

2. Koutsilieris M, Dimopoulos MA, Doillon C, Sourla A, ReyesMoreno C, Choki I. (1996) The molecular concept of prostate cancer. Cancer J. 9: 89-94.

3. Koutsilieris M. (1993) Osteoblastic metastases in advanced prostate cancer. Anticancer Res. 13: 443-449.

4. Koutsilieris M, Laroche B, Thabet M, Fradet Y. (1990) The assessment of disease aggressivity in stage D2 prostate cancer patients. Anticancer Res. 10: 333-336.

5. Guise TA, Mundy GR (1998) Cancer and bone. Endocr. Rev. 19: $18-54$.

6. Galasko CS. (1982) Mechanism of lytic and blastic metastatic disease of bone. Clin. Orthop. 12: 20-27.

7. Mundy GR. (1997) Mechanisms of bone metastasis. Cancer 80: $1546-1556$.

8. Koutsilieris M, Faure N, Tolis G, et al. (1986) Objective response and disease outcome in 59 patients with stage D2 prostatic cancer treated with either Buserelin or orchiectomy. Disease aggressivity and its association with disease response and outcome. Urology 27: 22 1-228.

9. Koutsilieris M, Mitsiades C, Sourla A. (2000) Insulin-like growth factor I and urokinase-type plasminogen activator bioregulation system as a survival mechanism of prostate cancer cells in osteoblastic metastases: development of antisurvival factor therapy for hormone-refractory prostate cancer. Mol. Med. 6: 251-267.

10. Mitsiades CS, Koutsilieris M. (2001) Molecular biology and cellular physiology of refractoriness to androgen ablation therapy in advanced prostate cancer. Expert Opin. Investig. Drug 10: 1099-1115.

11. Koutsilieris M. (1995) Skeletal metastases in advanced prostate cancer: cell biology and therapy. Crit. Rev. Oncol. Hematol. 18: 51-64.

12. Crawford ED, Eisenberger MA, McLeod DG, et al. (1989) A controlled trial of leuprolide with and without flutamide in prostatic carcinoma. N. Engl. J. Med 17: 419-424.

13. Behrakis P, Koutsilieris M. (1997) Pulmonary metastases in metastatic prostate cancer: host tissue-tumor cell interactions and response to hormone therapy. Anticancer Res. 17: 1517- 1518.

14. Tolis G, Koutsilieris M, Fazekas AT, Patton R. (1983) Transabdominal ultrasonography in the evaluation of patients with advanced prostatic carcinoma: effects of castration and of chronic administration of a gonadotrophin releasing hormone agonistic analogue. Prostate 4: 595-600.

15. Thomas RJ, Guise TA, Yin JJ, et al. (1993) Breast cancer cells interact with osteoclasts to support osteoclast formation. Endocrinology 140: 4451-4458.
16. Koutsilieris M, Frenette G, Lazure C, et al. (1993) Urokinasetype plasminogen activator: a paracrine factor regulating the bioavailability of IGFs in PA-III cell-induced osteoblastic metastases. Anticancer Res. 13: 481-486.

17. Goltzman D. (1997) Mechanisms of the development of osteoblastic metastases. Cancer 80: S1581-S1587.

18. Autzen P, Robson CN, Bjartell A, et al (1998) Bone morphogenetic protein 6 in skeletal metastases from prostate cancer and other common human malignancies. Br. J. Cancer 78: $1219-1223$.

19. Nelson JB, Hedican SP, George DJ, et al. (1995) Identification of endothelin-1 in the pathophysiology of metastatic adenocarcinoma of the prostate. Nat. Med. 1: 944-949.

20. Nelson JB, Nguyen SH, Wu-Wong JR, et al. (1999) New bone formation in an osteoblastic tumor model is increased by endothelin-1 overexpression and decreased by endothelin A receptor blockade. Urology 53: 1063-1069.

21. Lee MV, Fong EM, Singer FR, Guenette RS. (2001) Bisphosphonate treatment inhibits the growth of prostate cancer cells. Cancer Res. 61: 2602-2608.

22. Reyes-Moreno C, Sourla A, Choki I, et al. (1998) Osteoblastderived survival factors protect PC-3 human prostate cancer cells from adriamycin apoptosis. Urology 52: 341-347.

23. Koutsilieris M, Mitsiades C, Dimopoulos T, et al. (2002) Combination of dexamethasone and a somatostatin analogue in the treatment of advanced prostate cancer. Expert Opin. Investig. Drugs 11: 283-293.

24. Koutsilieris M, Mitsiades C, Dimopoulos T, et al. (2001) A combination of dexamethasone and a somatostatin analogue reintroduces objective clinical responses to LHRH analog in androgen ablation-refractory prostate cancer patients. J. Clin. Endocrinol. Metab. 86: 5729-5736.

25. Gomella LG, Raj GV, Moreno JG. (1997) Reverse transcriptase polymerase chain reaction for prostate specific antigen in the management of prostate cancer. J. Urol. 158: 326-337.

26. Deguchi T, Yang M, Ehara H, et al. (1997) Detection of micrometastatic prostate cancer cells in the bone marrow of patients with prostate cancer. Br. J. Cancer 75: 634-638.

27. Cama C, Olsson CA, Raffo AJ, et al. (1995) Molecular staging of prostate cancer. II. A comparison of an enhanced reverse transcriptase polymerase chain reaction assay for prostate specific antigen versus prostate specific membrane antigen. $J$. Urol. 153: 1373-1378.

28. Frith JC, Monkkonen J, Blackburn GM, et al. (1997) Clodronate and liposome-encapsulated clodronate are metabolized to a toxic ATP analog, adenosine 5'-b,g-dichloromethylene) triphosphate, by mammalian cells in vitro. J. Bone Miner. Res. 12: 1358-1367.

29. Russell RGG, Rogers MJ, Frith JC, et al. (1999) The pharmacology of bisphosphonates and new insights into their mechanism of action. J. Bone Miner. Res. 14: 56-65.

30. Luckman SP, Hughes DE, Coxon FP, et al. (1998) Nitrogencontaining bisphosphonates inhibit the mevalonate pathway and prevent post-transnational prenylation of GTP-binding proteins including Ras. J. Bone Miner. Res. 13: 581-589.

31. Van Beek E, Lowik C, van der Pluijm G, Papadopoulos S. (1999) The role of geranylgeranylation in bone resorption and its suppression by bisphosphonates in fetal bone explants in vitro: a clue to the mechanism of nitrogencontaining bisphosphonates. J. Bone Miner. Res. 14: 722-729.

32. Alvarez L, Guanabens N, Peris P, et al. (2001) Usefulness of biochemical markers of bone turnover in assessing response to the treatment of Paget's disease. Bone 29: 447-452.

33. Zimering MB. (2002) Effect of intravenous bisphosphonates on release of basic fibroblast growth factor in serum of patients with cancer-associated hypercalcemia. Life Sci. 70: 1947-1960.

34. Charhon SA, Chapuy MC, Delvin EE, et al. (1983) Histomorphometric analysis of sclerotic bone metastases from prostatic carcinoma with special reference to osteomalacia. Cancer 51: 918-924.

35. Urwin GH, Percival RC, Harris S, et al. (1985) Generalized increase in bone resorption in carcinoma of the prostate. Eur. J. Urol. 57: 721-723. 
36. Percival RC, Urwin GH, Harris S, et al. (1987) Biochemical and histological evidence that carcinoma of the prostate is associated with increased bone resorption. Eur. J. Surg. Oncol. 13: 41-49.

37. Clarke NW, McClure J, George NJR. (1991) Morphometric evidence for bone resorption and replacement in prostate cancer. Br. J. Urol. 68: 74-80.

38. Taube T, Kylmala T, Lamberg-Allardt C, Tammela TL, Elomaa I. (1994) The effect of clodronate on bone in metastatic prostate cancer. Histomorphometric report of a double blind randomized placebo-controlled study. Eur. J. Cancer. 30: $751-758$.

39. Ikeda I, Miura T, Kondo I. (1996) Pyridinium cross-links as urinary markers of bone metastases in patients with prostate cancer. Br. J. Urol. 77: 102-106.

40. Maeda H, Koizumi M, Yoshimura K, et al. (1997) Correlation between bone metabolic markers and bone scan in prostatic cancer. J. Urol. 157: 539-543.

41. Suda T, Takahashi N, Udagawa N, et al. (1999) Modulation of osteoclast differentiation and function by the new members of the tumor necrosis factor receptor and ligand families. Endocr. Rev. 20: 345-357.

42. Boissier S, Ferreras M, Peyruchaud O. (2000) Bisphosphonates inhibits breast and prostate carcinoma cell invasion, an early event in the formation of bone metastasis. Cancer Res. 60: 2949-2954.

43. Mundy GR, Yoneda T. (1998) Bisphosphonates as anticancer drugs. N. Engl. J. Med. 339: 398-400.

44. Papadopoulos SE, Hamdy NAT, van der Pluijm G. (2000) Bisphosphonates in the management of prostatic carcinoma metastatic to the skeleton. Cancer 88: 3047-3053.

45. Bloomfield DJ. (1998) Should bisphosphonates be part of the standard therapy of patients with multiple myeloma or bone metastases from other cancers? An evidence based review. $J$. Clin. Oncol. 16: 1218-1225.

46. Van der Pluijm G, Vloedgraven H, van Beek E, et al. (1996) Bisphosphonates inhibit the adhesion of breast cancer cells to bone matrices in vitro. J. Clin. Invest. 98: 698-705.

47. Boissier S, Magnetto S, Frappart L, et al. (1997) Bisphosphonates inhibit prostate and breast carcinoma cell adhesion to unmineralized and mineralized bone extracellular matrices. Cancer Res. 57: 3890-3894.

48. Teronen O, Heikkila P, Konttinen YT, et al. (1999) MMP inhibition and down regulation by bisphosphonates. Ann. N. Y. Acad. Sci. 878: 453-465.

49. Wood J, Schnell C, Green J. (2000) Zolendronic acid (ZOMETA) a potent inhibitor of bone resorption, inhibits proliferation and induces apoptosis in human endothelial cells in vitro and is antiangiogenic in a murine growth factor implant model. Proc. Am. Soc. Clin. Oncol. 19: Abstract 2620.

50. Miller PD. (2001) Bisphosphonates adjuvant therapy for prostate cancer. Proceedings of the 11th International Prostate Cancer Update, Colorado, January 31-February 4, pp. 302-304.

51. Lipton A, Small I, Saad F, et al. (2002) The new bisphosphonate Zometa decreases skeletal complications in both lytic and blastic lesions. A comparison to pamidronate. Chemotherapy Foundation Symposium XIX: Innovative Cancer Therapy for Tomorrow.

52. Coleman RE. (2001) Should bisphosphonates be the treatment of choice for metastatic bone disease? Semin. Oncol. 28: $35-41$.

53. Carey PO, Lippert MC. (1988) Treatment of painful prostatic bone metastases with oral etidronate disodium. Urology 32: 403-407.

54. Smith JA. (1989) Palliation of painful bone metastases from prostate cancer using sodium etidronate. Results of a randomized, prospective, double blind, placebo-controlled study. J. Urol. 141: 85-87.

55. Adami S, Salvagno G, Guarrera G, et al. (1985) Dichloromethylene diphosphonate in patients with prostatic carcinoma metastatic to the skeleton. J. Urol. 134: 1152-1154.
56. Adami S, Mian M. (1989) Clodronate therapy of metastatic bone disease in patients with prostatic carcinoma. Recent Results. Cancer Res. 116: 67-72.

57. Vorreuther R. (1993) Bisphosphonates as an adjunct to palliative therapy of bone metastases from prostatic carcinoma. A pilot study on clodronate. Br. J. Urol. 72: 792-795.

58. Cresswell SM, English PJ, Hall RR, Roberts JT, Marsh MM. (1995) Pain relief and quality-of-life assessment following intravenous and oral clodronate in hormone-escaped metastatic prostate cancer. Br. J. Urol. 76: 360-365.

59. Elomaa I, Kylmala T, Tammela T, et al. (1992) Effect of oral clodronate on bone pain. A controlled study in patients with metastatic prostate cancer. Int. Urol. Nephrol. 24: 159-166.

60. Masud T, Slevin ML. (1989) Pamidronate to reduce bone pain in normocaelcemic patient with disseminated prostatic carcinoma. Lancet 1: 1021-1022.

61. Pelger RCM, Lyclama A, Nijeholt AAB, Papadopoulos SE. (1989) Short-term metabolic effects of pamidronate in patients with prostatic carcinoma and bone metastases. Lancet 2: 865.

62. Clarke NW, McClure J, George JR. (1991) Morphometric evidence for bone resorption and replacement in prostate cancer. Br. J. Urol. 68: 74-80.

63. Clarke NW, McClure J, George NJR. (1992) Disodium pamidronate identifies differential osteoclastic bone resorption in metastatic prostate cancer. Br. J. Urol. 69: 64-70.

64. Lipton A, Clover D, Harvey H, et al. (1994) Pamidronate in the treatment of bone metastases: results of 2 dose-ranging trials in patients with breast or prostate cancer. Ann. Oncol. 5: S31-S35.

65. Pelger RCM, Hamdy NAT, Zinderman AH, et al. (1998) Effects of the bisphosphonate olpadronate in patients with carcinoma of the prostate metastatic to the skeleton. Bone 22: 403-408.

66. Raghavan D, Wallace M. (1990) Preemptive (neoadjuvant) chemotherapy: can analysis of eligibility criteria, prognostic factors, and tumor staging from different trials provide valid or useful comparisons? Semin. Oncol. 17: 613-618.

67. Tannock IF. (1992) Is there evidence that chemotherapy is of benefit to patients with carcinoma of the prostate? J. Clin. Oncol. 3: 1013-1021.

68. Belliveau RE, Spencer RP. (1975) Incidence and staging of bone lesions detected by $99 \mathrm{mTc}$ polyphosphate scans in patients with tumors. Cancer 36: 65-72.

69. Galasko CS. (1976) Mechanisms of bone destruction in the development of skeletal metastases. Nature 263: 507-508.

70. Katz AE, de Vries GM, Begg MD, et al. (1995) Enhanced reverse transcriptase-polymerase chain reaction as an indicator of true pathologic stage in patients with prostate cancer. Cancer 75: 1642-1648.

71. Grasso YZ, Gupta MK, Levin HS, Zippe CD, Klein EA. (1998) Combined nested rt-PCR assay for prostate specific antigen and prostate specific membrane antigen in prostate cancer patients: correlation with pathologic stage. Cancer Res. 58: 1456-1459.

72. Loric S, Dumas F, Eschwege P, et al. (1995) Enhanced detection of hematogenous circulating prostatic cells in patients with prostate adenocarcinoma by using nested reverse trancriptase polymerase chain reaction assay based on prostate specific membrane antigen. Clin. Chem. 41: 1698-1704.

73. Melchior SW, Corey E, Ellis WJ, et al. (1997) Early tumor cell dissemination in patients with clinically localized carcinoma of the prostate. Clin. Cancer Res. 3: 249-256.

74. Olsson CA, de Vries MC, Benson MC, et al. (1996) The use of rt-PCR for prostate specific antigen assay to predict surgical failures before radical prostatectomy: molecular staging of the prostate cancer. Br. J. Urol. 77: 411-417.

75. Israeli RS, Miller WH Jr, Su SL, et al. (1994) Sensitive reverse transcriptase polymerase chain reaction detection of circulating prostatic tumor cells: comparison of prostate-specific membrane antigen and prostate-specific antigen-based assays. Cancer Res. 54: 6306-6310. 
76. Kibel AS, Krithivas K, Shamel B, Kantoff PW, DeWolf WC. (1996) Constitutive expression of high levels of prostate antigen in the absence of prostate carcinoma. Urology 48: 741-746.

77. Eschwege P, Dumas F, Blancet P, et al. (1995) Heamatogenous dissemination of prostatic epithelial cells during radical prostatectomy. Lancet 346: 1528-1530.

78. Koutsilieris M, Lembessis P, Luu-The V, Sourla A. (1999) Repetitive and site-specific molecular staging of prostate cancer using reverse transcriptase polymerase chain reaction for PSA and PSMA. Clin. Exp. Metastases 17: 823-830.
79. Sourla A, Lembessis P, Mitsiades C, et al, (2001) Conversion of nested reverse-transcriptase polymerase chain reaction from positive to negative status at peripheral blood during androgen ablation therapy is associated with long progression-free survival in stage D2 prostate cancer patients. Anticancer Res. 21: 3665-3570.

80. Lembessis P, Sourla A, Mitsiases C, Koutsilieris M. (2002) Significance of molecular staging in clinically localized and advanced stage prostate cancer. In Labrie F, Koutsilieris M (eds). Prostate Cancer: Understanding the Pathophysiology and Redesigning the Treatment. (in press). 